\title{
Is There Any Relationship between Human Herpesvirus-8 and Multiple Myeloma?
}

\section{Mohammad Hadi Sadeghian, ${ }^{1}$ Maryam Mohammadnia Avval, ${ }^{2}$ Hossein Ayatollahi, ${ }^{1}$ Mohammad Reza Keramati, ${ }^{3}$ Bahram Memar, ${ }^{2}$ Saeed Amel Jamedar, ${ }^{4}$ Maryam Sheikhi, ${ }^{1}$ and Gohar Shaghayegh ${ }^{1}$}

${ }^{1}$ Cancer Molecular Pathology Research Centre, Faculty of Medicine, Ghaem Medical Centre, Mashhad University of Medical Sciences, Mashhad, Iran

${ }^{2}$ Faculty of Medicine, Mashhad University of Medical Sciences, Mashhad, Iran

${ }^{3}$ Cancer Molecular Pathology Research Centre, Faculty of Medicine, Imam Reza Medical Centre, Mashhad University of Medical Sciences, Mashhad, Iran

${ }^{4}$ Department of Microbiology, Faculty of Medicine, Mashhad University of Medical Sciences, Mashhad, Iran

Correspondence should be addressed to Hossein Ayatollahi; hossein.ayatollahi@yahoo.com

Received 21 November 2012; Revised 18 January 2013; Accepted 26 January 2013

Academic Editor: L. Arcaini

Copyright (C) 2013 Mohammad Hadi Sadeghian et al. This is an open access article distributed under the Creative Commons Attribution License, which permits unrestricted use, distribution, and reproduction in any medium, provided the original work is properly cited.

\begin{abstract}
Background. Human herpesvirus-8 (HHV-8) is associated with some human diseases including Kaposi's sarcoma and also some B-cell lymphoproliferative disorders. Few studies have highlighted the potential role of HHV-8 in the development of multiple myeloma (MM) which is known as a malignant proliferation of plasma cells derived from a single clone. Aims. The aim of this study was to find a relationship between HHV-8 and MM using polymerase chain reaction (PCR) method. Materials and Methods. This study was conducted on 30 formalin-fixed, paraffin-embedded (FFPE) bone marrow biopsies of multiple myeloma and 30 normal FFPE bone marrow biopsies. After the sample preparation, Deoxyribonucleic acid (DNA) was extracted by nonheating procedure. PCR for HHV-8 virus was carried out with commercial kit and the PCR products were visualized by gel electrophoresis. Finally, the statistical analysis was performed. Results. HHV-8 virus was not detected by PCR from FFPE blocks of multiple myeloma samples, while only one of the controls showed DNA band of the corrected molecular weights. Fisher's exact test showed that no statistical differences were found between the two groups $(P=0.999)$. Conclusion. Our report adds to the body of evidence that there is no association between HHV- 8 and MM against a major role of HHV-8 infection in the pathogenesis of clonal plasma cell proliferation.
\end{abstract}

\section{Introduction}

Human herpesvirus-8 (HHV-8), also called Kaposi's sarcoma-associated herpesvirus (KSHV), is a member of the gamma herpesvirus family [1]. This virus was first identified in Kaposi's sarcoma tissues obtained from patients with acquired immunodeficiency syndrome (AIDS) by Chang et al. in 1994 [2]. It has been implicated that HHV-8 may be associated with some human diseases including primary effusion lymphoma, a rare subtype of B-cell nonHodgkin's lymphoma (NHL) [3], multicentric Castleman disease [4], angiosarcoma [5], angiolymphoid hyperplasia with eosinophilia [6], sarcoidosis [7], squamous cell carcinoma [8], pityriasis rosea [9], and multiple myeloma (MM) [10].

Multiple myeloma or plasma cell myeloma is a hematologic malignancy caused by neoplastic plasma cells which synthesize abnormal amounts of monoclonal immunoglobulins or immunoglobulin fragments [11]. This is primarily a disease of the middle-aged and the elderly with a median age at diagnosis of about 62 years [12] that affects slightly more men than women [13]. Plasma cell myeloma is the second most common blood malignancy in USA after NHL, causing about $1 \%$ of human malignancies and $13 \%$ of hematological neoplasms [12]. It is found that about 86,000 incident cases 
occur each year [14]. The incidence of MM in the Europeans and Americans is about 4-6 persons-illness for each 100000 populations [15]. MM is rare among some Asian descents such as the Japanese [11]. According to Mozaheb et al., the frequency of plasma cell neoplasm is $10.9 \%$ of lymphoid malignancies in Mashhad, Iran [16].

The etiology of MM is usually unknown. Some studies have suggested a pivotal role of viruses in the development of MM. Yee et al. [17] and Elira Dokekias et al. [18] found a possible correlation between human immunodeficiency virus and MM. Another study by Franceschi showed that chronic hepatitis B virus infection may increase the risk of MM in healthy European candidates [19]. There are some data that show a possible relevance between HHV-8 and MM [10, 20, 21]. This virus contains genes that encode human cytokines homologues; one of them is viral interleukin-6 (vIL-6) that is a biologically active homologue of human IL-6. IL-6 is a survival factor of plasma cells and a significant growth factor for myeloma cells $[22,23]$. However, some other studies have not found any connection between HHV-8 and multiple myeloma [24-26]. These conflicting results emphasize the necessity for more research on this issue. Thus, in order to clarify the conflicting results between different studies we investigated samples from MM cases with a different ethnic origin. The aim of this study was to find the feasible relation between HHV-8 and MM using polymerase chain reaction (PCR) method.

\section{Materials and Methods}

This case-control study was conducted on 30 formalin-fixed, paraffin-embedded (FFPE) bone marrow biopsies of multiple myeloma and 30 normal FFPE bone marrow biopsies that had been archived in the Pathology Department of Ghaem Hospital of Mashhad University, Iran, since October 2004 to October 2010. Medical history and laboratory reports of the two groups were perused and two pathologists investigated archived slides. In case group, the patients had more than $30 \%$ plasma cells in bone marrow; all of them were in symptomatic phase of multiple myeloma and they did not have any positive test results for HIV or HCV. Control group was comprised of lymphoma patients with normal bone marrow biopsy. The myeloma (or case) and normal (or control) groups were equally matched in proportion to gender and age.

2.1. DNA Extraction. Each paraffin block was cut at $10 \mu \mathrm{m}$ and ten to fifteen sections of each were carefully collected in a sterile microtube. Non-heating DNA extraction protocol was used for DNA extraction [27]. The amount of DNA was defined by using the Thermo Scientific NanoDrop 2000 Spectrophotometer and inadequate specimens were excluded. All steps were done under sterile status.

2.2. PCR Amplification. We used the PCR Kit (DNA Technology JSC, PCR Kit, Moscow, Russia) for DNA amplification. PCR procedures were done following the instruction of the kit: $10 \mu \mathrm{L}$ of Taq-polymerase solution were added into each tube with paraffin-sealed amplification mixture and then $5 \mu \mathrm{L}$
TABLE 1: The laboratory results of multiple myeloma patients in our study.

\begin{tabular}{lcccc}
\hline & Minimum & Maximum & Mean & SD \\
\hline Hemoglobin & 6.3 & 15.5 & 10.2 & 2.6 \\
RBC & 2.0 & 3.4 & 5.1 & 0.8 \\
WBC & 0.5 & 17.3 & 6.5 & 3.7 \\
PLT & 5.8 & 534 & 234.5 & 109 \\
ESR & 30 & 132 & 75.6 & 34.2 \\
Calcium & 8.1 & 11.9 & 9.4 & 0.8 \\
Creatinine & 0.6 & 9.1 & 2.2 & 2.0 \\
LDH & 240 & 2012 & 604.9 & 76.1 \\
\hline
\end{tabular}

Red blood cell, white blood cell, platelet, erythrocyte sedimentation rate, and lactate dehydrogenase.

of DNA sample were added and were spun at $1000 \mathrm{rpm}$ for 35 seconds. For positive control, we used the positive control sample of the kit and for negative control, $5 \mu \mathrm{L}$ of processed negative control sample of the kit were added. Ultimately, we placed the tubes into PCR Cycler (Applied Biosystems Veriti Thermal Cycler) and run the program: 180 seconds at $94^{\circ} \mathrm{C}$ for the first step and then 50 seconds at $94^{\circ} \mathrm{C}, 50$ seconds at $64^{\circ} \mathrm{C}$, and 50 seconds at $72^{\circ} \mathrm{C}$ for 45 cycles. After amplification, $5 \mu \mathrm{L}$ of each sample was run on a $2 \%$ agarose gel, stained with ethidium bromide, and then photographed. The expected size of the PCR product for HHV8 genome was $293 \mathrm{bp}$. Beta-globin gene with $560 \mathrm{bp}$ lengths was used as an internal control.

2.3. Statistical Analysis. Data management and analysis was performed using SPSS V.11 (statistical software for social analysis-version 18). We compared case and control groups with $t$-test, Pearson chi-square test, and Fischer's exact test for age, sex, and PCR results, respectively. Differences were statistically significant at $P<0.05$.

\section{Results}

A total of 60 bone marrow biopsies were included comprising 30 myeloma patients and the same number of normal (control) bone marrow tissues. For each set, the age range was 40-80 years; the mean \pm standard deviation (SD) of age in the case and control group was $63.6 \pm 9.6$ and $63.4 \pm 10.7$, respectively. There were no significant differences between the two groups, analysed by independent $t$-test $(P=0.95)$.

In case group, 14 males (46.7\%) and 16 females (53.3\%) participated and in control group 16 patients (53.3\%) and 14 patients (46.7\%) were males and females, respectively. Pearson chi-square test showed no significant differences between case and control groups $(P=0.61)$. Our patients' laboratory results are shown in Table 1.

The minimum, maximum, and mean \pm SD of bone marrow plasma cells were 35,90 , and $60.36 \pm 14.42$, respectively. No HHV-8 virus DNA band was detected in MM samples, while one of the control cases showed DNA band of the corrected molecular weights (Figure 1). By using Fisher's exact test, no statistical differences were found between the two groups $(P=0.999)$. The concentration of DNA was 


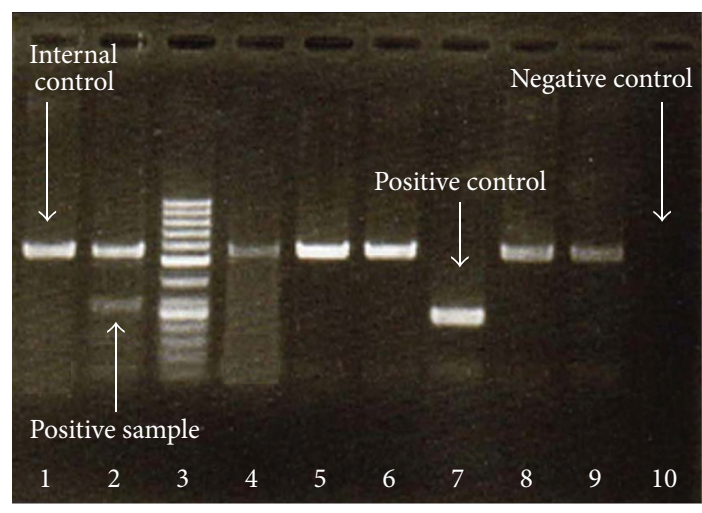

FIGURE 1: Electrophoresis of amplified PCR products for HHV8 DNA. Line 1: internal control, Line 7: positive control, Line 10: negative control, Line 3: size marker, Lines 1, 4, 5, 6, 8, and 9: negative results, and Line 2: positive sample.

checked again by NanoDrop to rule out of false negative results. The HHV-8 positive case was a 67 -year-old male with history of large cell lymphoma.

\section{Discussion}

$\mathrm{HHV}-8$ is a lymphotropic virus that has been implicated as causative agent in some lymphomas such as AIDS-related body cavity-based lymphoma and plasmablastic lymphoma, a subgroup of large B-cell lymphoma arising in $\mathrm{HHV}$ 8-associated multicentric Castleman disease [23, 28, 29]. The etiology of MM is not well understood. Although the results of our study demonstrated that there is no significant relationship between MM and HHV-8 infection, some other studies have considered $\mathrm{HHV}-8$ as a possible etiology of MM $[10,20,21]$. It has been suggested that HHV-8 encoded cytokine homologues including vIRF, vIL-8R, and vIL-6 that may play an important role in the pathogenesis of $\mathrm{MM}$ [30]. Latency-associated nuclear antigen (LANA)-1 of HHV8 causes inhibition of apoptosis and maintenance of latency; then it has an important role in the pathogenesis of related malignancies. Some cellular proteins homologues such as cytokines, chemokines, and cell-cycle regulators are made by $\mathrm{HHV}-8$; these viral proteins are imitating host protein signals and preparing microenvironment for tumor growth [31].

The first data about the presence of HHV-8 in bone marrow dendritic cells of MM patients was reported by Rettig et al. in 1997 [20]. They demonstrated the evidence of HHV-8 infection in cultured bone marrow dendritic stromal cells in all of 15 samples obtained from patients with MM and in two out of eight samples from patients with monoclonal gammopathy of indefinite significance (MGUS). They established that the HHV-8 infection may stimulate the growth of uninfected plasma cell clones and also may promote MM transformation to MGUS. In a case-control study that was done by Raje et al., similar results were achieved. They found the presence of HHV-8 in $88.8 \%$ bone marrow samples of MM patients, $37.5 \%$ normal bone marrow cells, and 33.3\% normal donor peripheral blood cells by applying nested PCR [32]. In another study, Chauhan et al. examined the potential of HHV-8 by means of PCR in USA. HHV-8 genome was identified in bone marrow stromal cells in 24/26 (92\%) patients with MM and 1/4 normal subjects, but HHV-8 antibodies were not detected in sera obtained from either MM patients or controls [33]. The rate of HHV-8 positivity in MM patients was also reported as $69.6 \%$ by realtime PCR and as $82.6 \%$ by nested PCR [34].

Despite these studies, other investigators published conflicting results [22, 35-40]. Olsen et al., in United States, searched for HHV-8 in MM patients by serology, PCR, and immunohistochemistry. All of the bone marrow aspirates or biopsies, peripheral blood mononuclear cells, or dendritic cell cultures were negative [35]. Cho and Lee performed another study in Korea and only 1 out of $26 \mathrm{MM}$ patients was positive for HHV-8 by PCR [36]. Tedeschi et al. evaluated HHV8 seroprevalences among $329 \mathrm{MM}$ patients and 1631 control subjects. HHV- 8 seropositivity was $12 \%$ and $15 \%$ in cases and controls, respectively. However, they could not find any association between $\mathrm{MM}$ and $\mathrm{HHV}-8$ seropositivity [37]. In our study, HHV-8 was not observed in patients with MM by PCR method in north east Iran. Therefore, our results did not established any relationship between HHV-8 and MM. Our paper adds to the body of evidence that HHV8 is not correlated with $\mathrm{MM}$ and is against a major role of HHV-8 infection in the pathogenesis of clonal plasma cell proliferation.

Then as shown here, there is considerable disagreeability in the published literature. There are some variations in HHV8 prevalence in different countries; $\mathrm{HHV}-8$ seropositivity in the general population is low in northern Europe, United States, and Asia, intermediate in Mediterranean countries, and high in sub-Saharan Africa [31], but there is no accurate report of its prevalence in Iran. The geographical and ethnic origin may be the reason for conflicting reports.

Different methodology may also play a role in this discrepancy. In our study, PCR is used for detecting HHV8. This method can be implemented in detecting the viral infection in FFPE tissue biopsies and is particularly useful for confirming the diagnosis of herpesviruses family. PCR has raised the sensitivity of viral detection beyond that of antigen assays or culture. In studies based on PCR analysis, conflicting results may be due to variations in the methods, primer sets, and target sequences. For example, the use of multiple-target HHV-8 sequences increases the ability of virus detection, but nested PCR method may induce false positive results [41].

In conclusion, our study did not demonstrate any association between HHV-8 and MM. To confirm our findings, further studies with larger sample size and different ethnicities may be carried out.

\section{Key Messages}

HHV-8 is associated with some diseases including Kaposi's sarcoma and some B-cell lymphomas. This study investigated the possible difference in the presence of HHV-8 genome in bone marrow tissue using the polymerase chain reaction method in patients with multiple myeloma and in control group. 


\section{Acknowledgments}

This study was the result of an M.D. student thesis proposal and financially supported by the Research Vice Chancellor of Mashhad University of Medical Sciences. The authors are thankful to them and to Dr. Mohammad Khajeh Daluei for the statistical advice.

\section{References}

[1] D. Ganem, "Kaposis sarcoma-associated herpes virus," in Fields Virology, D. M. Knipe and P. M. Howley, Eds., vol. 3, pp. 28472888, Lippincott Williams \& Wilkins, Philadelphia, Pa, USA, 5th edition, 2007.

[2] Y. Chang, E. Cesarman, M. S. Pessin et al., "Identification of herpesvirus-like DNA sequences in AIDS-associated Kaposi's sarcoma," Science, vol. 266, no. 5192, pp. 1865-1869, 1994.

[3] T. Ikebe, Y. Amemiya, M. Saburi et al., "Rare primary effusion lymphoma associated with HHV-8 in Japan," Internal Medicine, vol. 49, no. 13, pp. 1303-1306, 2010.

[4] J. Stebbing, C. Adams, A. Sanitt et al., "Plasma HHV8 DNA predicts relapse in individuals with HIV-associated multicentric Castleman disease," Blood, vol. 118, no. 2, pp. 271-275, 2011.

[5] K. N. Naresh, N. Francis, N. Sarwar, and M. Bower, "Expression of human herpesvirus 8 (HHV-8), latent nuclear antigen 1 (LANA1) in angiosarcoma in acquired immunodeficiency syndrome (AIDS) - a report of two cases," Histopathology, vol. 51, no. 6, pp. 861-864, 2007.

[6] P. Bhattacharjee, P. Hui, and J. McNiff, "Human herpesvirus8 is not associated with angiolymphoid hyperplasia with eosinophilia," Journal of Cutaneous Pathology, vol. 31, no. 9, pp. 612-615, 2004.

[7] L. Di Alberti, A. Piattelli, L. Artese et al., "Human herpesvirus 8 variants in sarcoid tissues," The Lancet, vol. 350, no. 9092, pp. 1655-1661, 1997.

[8] H. Qavi and A. A. Al-Rajhi, "Acetylcholinesterase and HHV-8 in squamous cell carcinoma and retinoblastoma," In Vivo, vol. 23, no. 5, pp. 679-683, 2009.

[9] A. Prantsidis, D. Rigopoulos, G. Papatheodorou et al., "Detection of human herpesvirus 8 in the skin of patients with pityriasis rosea," Acta Dermato-Venereologica, vol. 89, no. 6, pp. 604-606, 2009.

[10] S. I. Ismail, I. S. Mahmoud, M. A. L. Salman, M. A. Sughayer, and A. M. Mahafzah, "Frequent detection of Human Herpes Virus- 8 in bone marrow of Jordanian patients of multiple myeloma," Cancer Epidemiology, vol. 35, no. 5, pp. 471-474, 2011.

[11] K. Kaushansky, M. A. Lichtman, T. J. Kipps, U. Seligsohn, and P. T. Prchal, Williams Hematology, McGraw-Hill, New York, NY, USA, 8th edition, 2010.

[12] M. S. Raab, K. Podar, I. Breitkreutz, P. G. Richardson, and K. C. Anderson, "Multiple myeloma," The Lancet, vol. 374, no. 9686, pp. 324-339, 2009.

[13] S. H. Swerdlow, E. Campo, N. L. Harris et al., Eds., WHO Classification of Tumours of Haematopoietic and Lymphoid Tissues, IARC, Lyon, France, 2008.

[14] N. Becker, "Epidemiology of multiple myeloma," Recent Results in Cancer Research, vol. 183, pp. 25-35, 2011.

[15] B. J. Bain, D. M. Clark, and B. S. Wilkins, Bone Marrow Pathology, Wiley-Blackwell, 4th edition, 2010.

[16] Z. Mozaheb, A. Aledavood, and F. Farzad, "Distributions of major sub-types of lymphoid malignancies among adults in
Mashhad, Iran," Cancer Epidemiology, vol. 35, no. 1, pp. 26-29, 2011.

[17] T. T. Yee, K. Murphy, M. Johnson et al., "Multiple myeloma and human immunodeficiency virus-1 (HIV-1) infection," American Journal of Hematology, vol. 66, no. 2, pp. 123-125, 2001.

[18] A. E. Dokekias, M. Moutschen, M. F. Purhuence, F. Malanda, and A. Moyikoua, "Multiple's myeloma and HIV infection: report of 3 cases," Revue Medicale de Liege, vol. 59, no. 2, pp. 95-97, 2004.

[19] S. Franceschi, M. Lise, C. Trepo et al., "Infection with hepatitis $B$ and $C$ viruses and risk of lymphoid malignancies in the european prospective investigation into cancer and nutrition (EPIC)," Cancer Epidemiology Biomarkers and Prevention, vol. 20, no. 1, pp. 208-214, 2011.

[20] M. B. Rettig, H. J. Ma, R. A. Vescio et al., "Kaposi’s sarcomaassociated herpesvirus infection of bone marrow dendritic cells from multiple myeloma patients," Science, vol. 276, no. 5320, pp. 1851-1854, 1997.

[21] M. Beksac, M. Ma, C. Akyerli et al., "Frequent demonstration of human herpesvirus 8 (HHV-8) in bone marrow biopsy samples from Turkish patients with multiple myeloma (MM)," Leukemia, vol. 15, no. 8, pp. 1268-1273, 2001.

[22] P. Barozzi, L. Potenza, G. Riva et al., "B cells and Herpesviruses: a model of lymphoproliferation," Autoimmunity Reviews, vol. 7, no. 2, pp. 132-136, 2007.

[23] V. Kumar, A. K. Abbas, N. Fausto, and J. C. Aster, Robbins and Cotran Pathologic Basis of Diseaseed, Saunders Elsevier, Philadelphia, Pa, USA, 8th edition, 2010.

[24] M. H. Sadeghian, M. Katebi, H. Ayatollahi, and M. R. Keramati, "Immunohistochemical study association between human herpesvirus 8 and multiple myeloma," International Journal of Hematology, vol. 88, no. 3, pp. 283-286, 2008.

[25] R. Duprez, V. Lacoste, S. Hermouet et al., "Plasma-cell leukemia and human herpesvirus 8 infection," Leukemia, vol. 18, no. 11, pp. 1903-1904, 2004.

[26] W. Chen, Q. Huang, C. W. Zuppan et al., "Complete absence of $\mathrm{KSHV} / \mathrm{HHV}-8$ in posttransplant lymphoproliferative disorders an immunohistochemical and molecular study of 52 cases," American Journal of Clinical Pathology, vol. 131, no. 5, pp. 632639, 2009.

[27] S. R. Shi, R. J. Cote, L. Wu et al., "DNA extraction from archival formalin-fixed, paraffin-embedded tissue sections based on the antigen retrieval principle: heating under the influence of $\mathrm{pH}$," Journal of Histochemistry and Cytochemistry, vol. 50, no. 8, pp. 1005-1011, 2002.

[28] C. Eaton, R. Dorer, and D. M. Aboulafia, "Human herpesvirus8 infection associated with kaposi sarcoma, multicentric castleman's disease, and plasmablastic microlymphoma in a man with AIDS: a case report with review of pathophysiologic processes," Pathology Research International, vol. 2011, Article ID 647518, 6 pages, 2011.

[29] A. Carbone, E. Cesarman, M. Spina, A. Gloghini, and T. F. Schulz, "HIV-associated lymphomas and gamma-herpesviruses," Blood, vol. 113, no. 6, pp. 1213-1224, 2009.

[30] C. Y. Zhang, "The role of human herpesvirus- 8 infection in the pathogenesis of multiple myeloma," Zhongguo Shi Yan Xue Ye Xue Za Zhi, vol. 10, no. 1, pp. 81-84, 2002.

[31] H. Fukumoto, T. Kanno, H. Hasegawa, and H. Katano, "Pathology of Kaposi's sarcoma-associated herpesvirus infection," Frontiers in Microbiology, vol. 2, article 175, 2011. 
[32] N. Raje, J. Gong, D. Chauhan et al., "Bone marrow and peripheral blood dendritic cells from patients with multiple myeloma are phenotypically and functionally normal despite the detection of Kaposi's sarcoma herpesvirus gene sequences," Blood, vol. 93, no. 5, pp. 1487-1495, 1999.

[33] D. Chauhan, A. Bharti, N. Raje et al., "Detection of Kaposi's sarcoma herpesvirus DNA sequences in multiple myeloma bone marrow stromal cells," Blood, vol. 93, no. 5, pp. 1482-1486, 1999.

[34] Y. Dong, P. Zhu, and M. Ma, "Quantitative analysis of human herpes virus type 8 and expression of its genes in patients with multiple myeloma," Zhonghua Yi Xue Za Zhi, vol. 81, no. 20, pp. 1230-1233, 2001.

[35] S. J. Olsen, K. Tarte, W. Sherman et al., "Evidence against KSHV infection in the pathogenesis of multiple myeloma," Virus Research, vol. 57, no. 2, pp. 197-202, 1998.

[36] M. S. Cho and S. N. Lee, "Questionable role of human herpesvirus- 8 in the pathogenesis of multiple myeloma," The Korean Journal of Pathology, vol. 39, pp. 164-167, 2005.

[37] R. Tedeschi, T. Luostarinen, P. De Paoli et al., "Joint Nordic prospective study on human herpesvirus 8 and multiple myeloma risk," British Journal of Cancer, vol. 93, no. 7, pp. 834837, 2005.

[38] N. Regamey, V. Hess, J. Passweg et al., "Infection with human herpesvirus 8 and transplant-associated gammopathy," Transplantation, vol. 77, no. 10, pp. 1551-1554, 2004.

[39] S. Hermouet, C. A. Sutton, T. M. Rose et al., "Qualitative and quantitative analysis of human herpesviruses in chronic and acute B cell lymphocytic leukemia and in multiple myeloma," Leukemia, vol. 17, no. 1, pp. 185-195, 2003.

[40] J. J. Drabick, B. J. Davis, J. H. Lichy, J. Flynn, and J. C. Byrd, "Human herpesvirus 8 genome is not found in whole bone marrow core biopsy specimens of patients with plasma cell dyscrasias," Annals of Hematology, vol. 81, no. 6, pp. 304-307, 2002.

[41] L. Pan, L. Milligan, J. Michaeli, E. Cesarman, and D. M. Knowles, "Polymerase chain reaction detection of kaposi's sarcoma-associated herpesvirus-optimized protocols and their applicationto myeloma," Journal of Molecular Diagnostics, vol. 3, no. 1, pp. 32-38, 2001. 


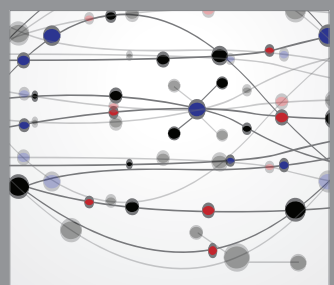

The Scientific World Journal
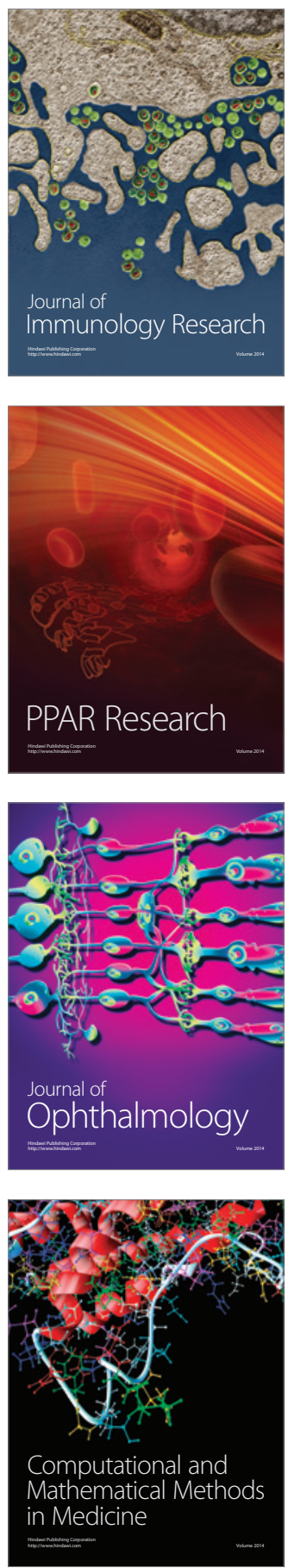

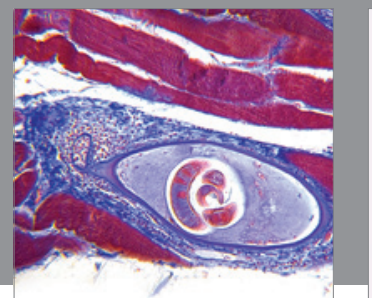

Gastroenterology

Research and Practice
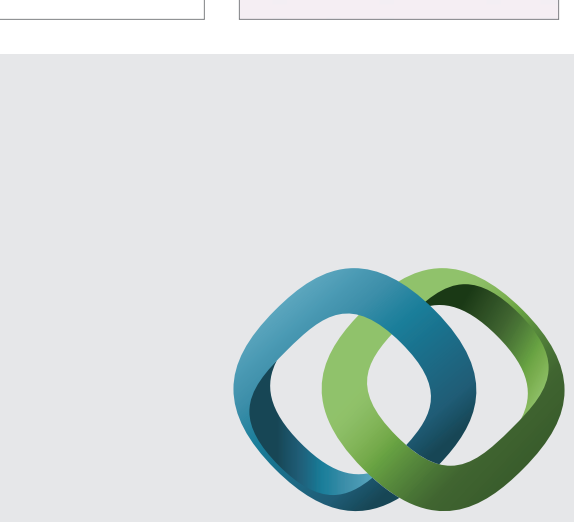

\section{Hindawi}

Submit your manuscripts at

http://www.hindawi.com
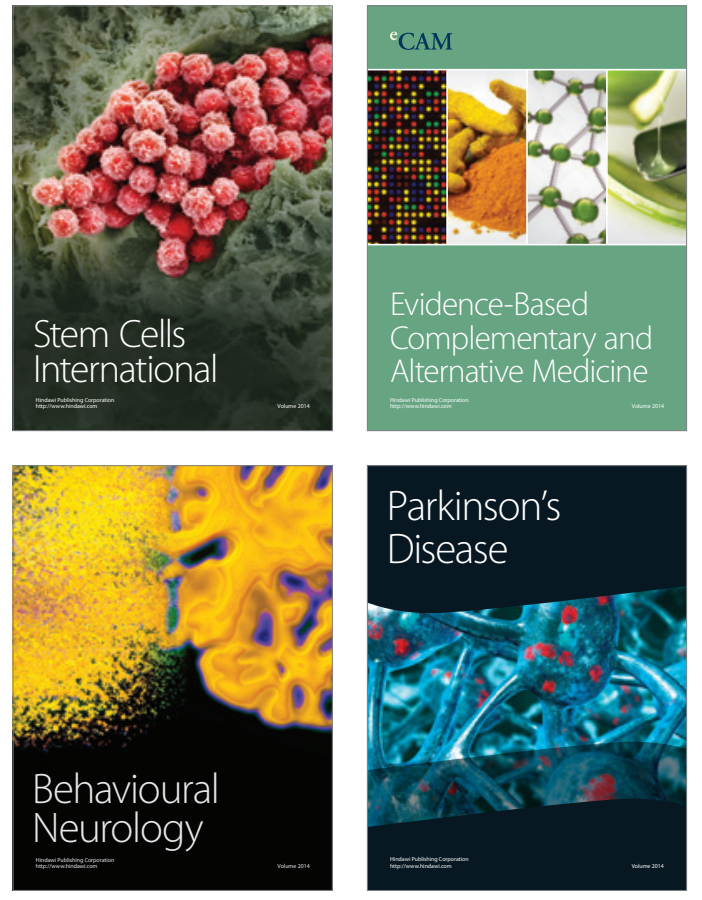
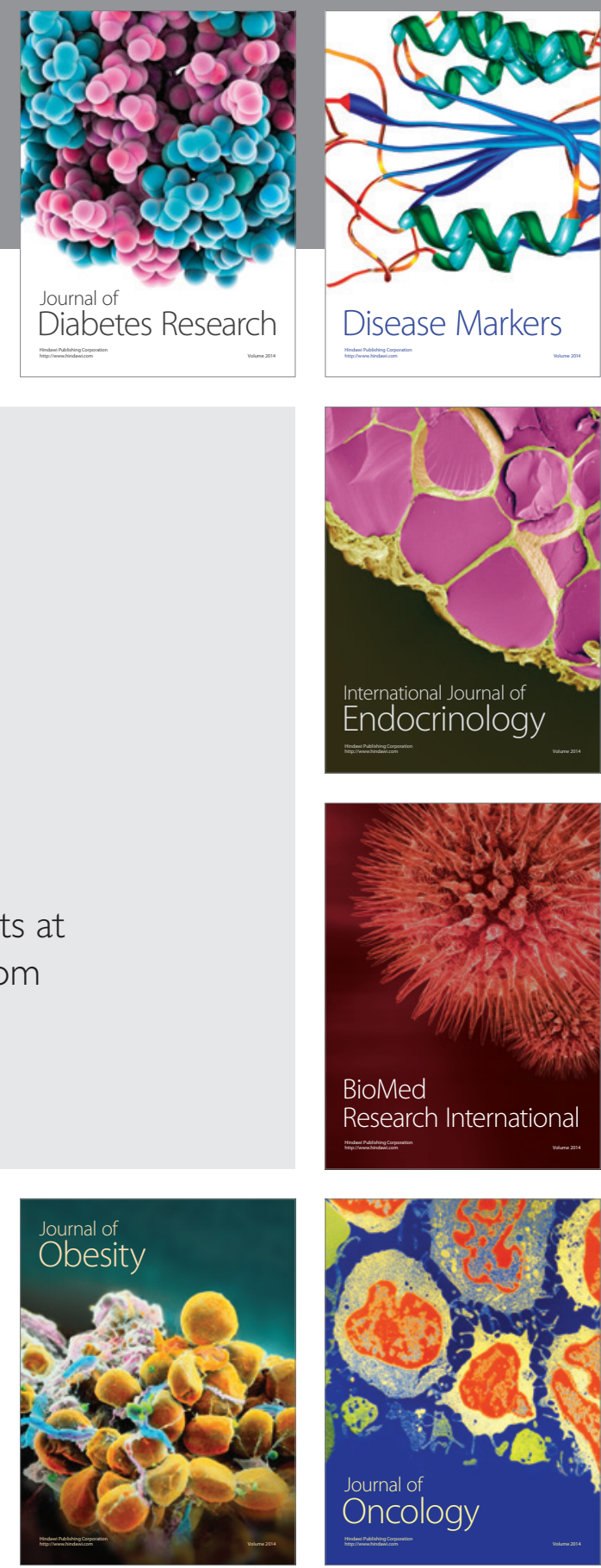

Disease Markers
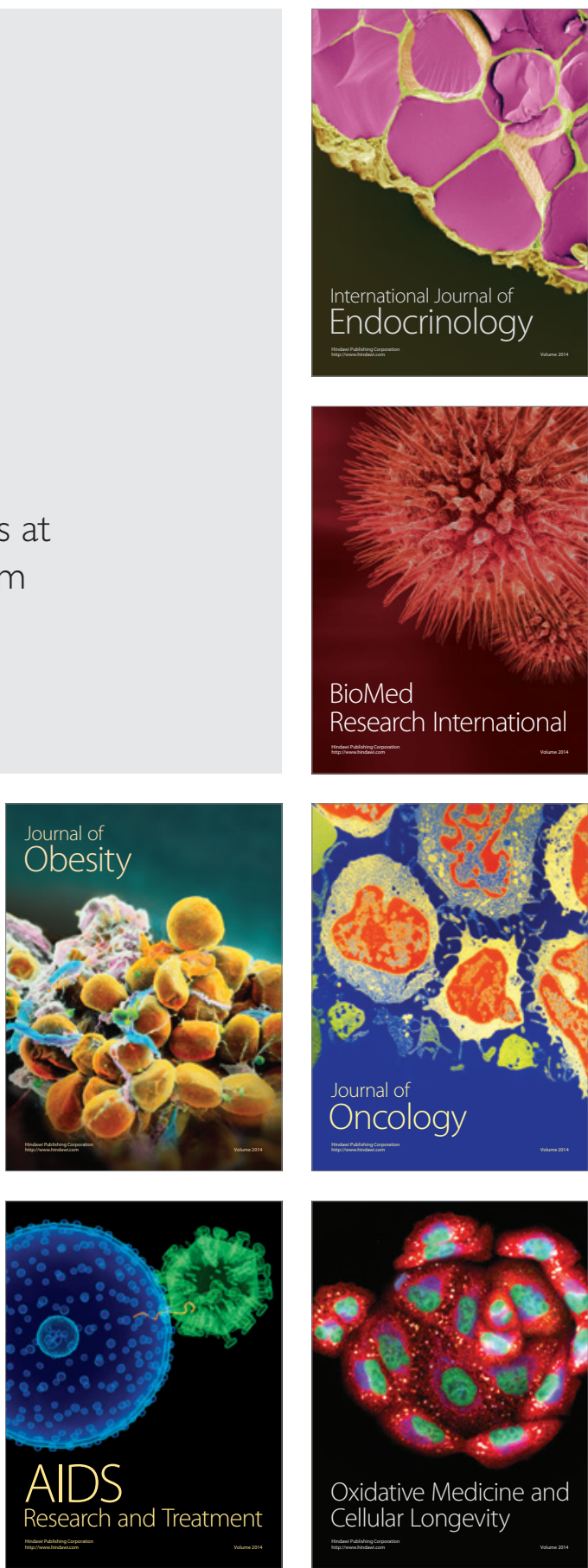